\section{Science in India discussed}

SIR - Your correspondence columns have recently attracted views on Indian science from many well-intentioned scientists at home and abroad, but most contributions have failed to evaluate the plight of Indian science from the perspective of our sociocultural value system. Scientists are not dissociated from the society in which they live and work.

Science is an intellectual, dynamic exercise based on rationality, logic and objectivity. It creates new knowledge which leads to progress in an atmosphere conducive to independence of thought. No one can claim sole proprietorship. On the other hand, our social values have been feudalistic for ages, and give precedence to personality and myth over principle and mind. Sycophancy over competence is the general rule rather than the exception in India. Science cannot be conducted in social isolation and vacuum, so finds itself on a collision course with our social values.

It was not until the late 1950 s that India began to build an infrastructure for "experimental sciences" under the national science policy resolution mandate to achieve scientific self-reliance for industrial development. Despite its meagre means, India has invested heavily in this enterprise, yet in three decades, the overall return has been small. Money is being spent in the wrong places.

At the national laboratories, the quantity of instrumentation and equipment may be limited, but the quality is comparable with that of most Western laboratories. Indian scientists abroad have proved to be imaginative and productive. Yet Indian science has neither achieved international recognition nor has it found profound application in solving national problems. Even Prime Minister Mrs Indira Gandhi was recently (Nature, 307,$4 ; 1984$ ) quoted as asking, at a meeting of directors of national research laboratories, that if there "was no hope of the situation improving, was it not time just to close them down"? This frustration is understandable. We have both qualified personnel and resources. What is lacking is the organization to guarantee an environment conducive to productivity. It is time not to close laboratories down but to rescue them through constructive changes.

The universities are in desperate shape. Many of them are fast slipping to the status of undergraduate colleges, so that many research laboratories have become places for postgraduate training. This has forced them to depend upon PhD students for research, while senior scientists are in search of PhD students rather than doing things themselves on the bench. The universities need to be revitalized, to provide sound research training and to take this burden from the research institutes.

The national laboratories should define their goals in more specific terms. A system scientists. that assures personal independence and incentive within broad objectives needs to be introduced. Mechanisms need to be developed to monitor individual productivity, which must be rewarded in some manner within the means of the nation. Young Indian scientists established abroad should be attracted home to promote a productive scientific environment. Nothing has hurt the cause of Indian science more than the demoralization and repression of young scientists. The forces of feudalism continue to choke Indian science. The time is ripe for the political leadership to become sophisticated and assert itself.

ChandRa Kant MitTal

Department of Basic Sciences,

\section{University of Illinois}

College of Medicine,

Peoria, Illinois 61656, USA

SIR - The recent discussions in Nature on the state of scientific research in India sound like the familiar arguments between Indian-based scientists, who think they are the greatest patriots, and immigrant Indians, who think of themselves as better

The first thing to realize is that science is universal and cannot be nationalized. Science and technology are relatively new in Indian society, which has nurtured arts, music and mysticism for hundreds of years in predominantly feudalistic environments. Historically, scientific and technological revolution have advanced handin-hand with the development of a free market economy by which the spirit of adventure and competition is usually rewarded. The adaptation of scientific research as a culture may be a painfully slow process in a country which is still uncertain as to the socio-political system that would work best in holding the country together and utilizing its limited resources.

Second, the view that Indian scientists should concentrate only on problems relevant to the country is shortsighted. Teaching and research in basic physical and biological sciences has to be maintained on a firm ground for long-term gains.

I recently spent a year at the Indian Institute of Science in Bangalore. This leading research institute maintains a university atmosphere with a great degree of intellectual freedom. My experience was not entirely discouraging. However, a general feeling of complacency about limited achievements, perhaps consisten with the fatalistic attitude ingrained in our culture, seems to be a major deterrent to progress. But there was great dynamism among certain individuals in some younger research units. A few scientists had used their past associations with good US and European laboratories to establish new techniques in their laboratories.

In this connection (see Dr Majumdar's letter, Nature 308, 396; 1984), I see nothing wrong with receiving gifts from other (foreign) laboratories, which is a common practice among laboratories in the United States. But it should not be a permanent excuse for not improving the poor state of the industrial infrastructure needed to support basic research. The Indian Government, for example, has not encouraged private enterprise within the country or from abroad to compete and produce quality chemicals. In an earnest desire to improve the quality of science, however, the government has spent large sums of public money on a few national laboratories that have unfortunately been run more like bureaucratic offices than research institutes.

The hue and cry about the brain drain has really gone a little too far. In this age of highly effective communication, no brain has to be lost to a particular country. The Indian scientists working abroad can, and some do, help those in the country in small but useful ways such as with gifts of chemicals and new technical information. The fact is that our country is at present incapable of gainfully using all the immigrant brains if they were to return.

Gautam Sanyal.

Department of Cell Biology,

Mayo Medical School,

Rochester, Minnesota 55905, USA

SIR - I would be glad if you could rectify an erroneous statement made in your otherwise excellent survey of "Science in India" (Nature 308, 888; 1984). It is more accurate to say that $\mathrm{Dr}$ Kunthala Jayaraman is collaborating with the Laboratoire d'Enzymologie du CNRS at Gif-sur-Yvette, where the toxin gene has been cloned, and not, as written, in collaboration with "the CNRS laboratory near Paris". Near Paris there are some forty or fifty CNRS laboratories.

Directeur de Recherche,

J. SZULMAJSTER

Laboratoire d'Enzymologie du CNRS, 91190 Gif-Sur-Yvette, France

SIR - Regardless of whether the roots of certain conceptual and practical pitfalls in the Indian system are derived from past British rule or are due to our ingrained tendency to blame the past rule when things do not work, it is clear that certain changes are necessary to eliminate impediments to efficiency and speedier progress.

What is even clearer is that time is on India's side and, given the present support and momentum, India is creating the right set of conditions to overcome these difficulties. Overall, your summary of Indian science is bound to have a positive impact on the system which has many achievements to its credit - and a working telephone system should not be too far off.

HaRihara M. Mehendale

Department of Forensic Medicine,

Karolinska Institutet,

S-104 01 Stockholm 60, Sweden 